\title{
PRÁTICAS EDUCATIVAS: A PARTICIPAÇÃO DA MÃE E DA CRIANÇA NA DETERMINAÇÃO DAS ATIVIDADES DA ROTINA DIÁRIA ${ }^{+}$
}

\author{
EDUCATIONAL PRACTICES: JOINT PARTICIPATION OF MOTHERS AND \\ THEIR CHILDREN IN THE DETERMINATION OF DAILY ROUTINE ACTIVITIES
}

\begin{abstract}
Moreira LVdeC, Biasoli-Alves ZMM. Práticas Educativas: a participação da mãe e da criança na determinação das atividades da rotina diária. Rev Bras Crescimento Desenvol Hum. 2008; 18(1): 53-65.
\end{abstract}

Resumo: A aquisição da independência da criança pode ser favorecida ou não pelas práticas de educação utilizadas pela família com ela. O presente artigo pretende descrever como mães de nível superior de escolaridade lidam com este aspecto na educação de seus filhos de dois a sete anos de idade. Com este objetivo foram entrevistadas 50 mães ( 25 residentes em uma cidade de porte médio localizada no interior de São Paulo e 25 moram na capital de um dos estados nordestinos). Foram utilizadas 43 questões do "Roteiro Reestruturado de Biasoli-Alves e Graminha". Elas investigam se é a mãe, o filho ou ambos que direcionam as situações do dia-a-dia da criança. Os resultados revelam maior freqüência da determinação conjunta (cerca de $60 \%$ ), ou seja, mãe e criança tendem a decidir, em conjunto, qual a direção da situação da rotina diária.

Palavras-chave: Práticas educativas; pais e filhos; famílias urbanas de camada média.

\section{INTRODUÇ̃̃O}

O século XX trouxe muitas mudanças na maneira de se pensar a infância e as práticas de cuidado e educação dos filhos. Observa-se a existência de um conjunto grande de estudos sobre estas temáticas, em diferentes países, incluindo o Brasil; e os resultados apresentados são muito importantes ${ }^{1-5}$.

Resumindo características presentes em pesquisas, Biasoli-Alves ${ }^{1}$ menciona que, nas décadas iniciais do século XX, embora o olhar das mães sempre acompanhasse as crianças, elas usufruíam de grandes espaços para brincar, tendo a oportunidade de diversas e variadas atividades, podendo ainda determinar livremente o uso do seu tempo. Os adultos controlavam as crianças e exigiam obediência e bom comportamento, utilizando punições severas. Já nas décadas de 50 e 60, apesar do crescimento das cidades, do aumento na mobilidade das famílias e do surgimento da televisão, o controle do comportamento da criança continuou sendo importante, porém com menos punição. O modelo de educação da época comportava tanto a exigência quanto a afetividade, complementadas por pouca explicação, independência e expressão de oposição ou desagrado aos adultos. Dirigindo-se para o final do século XX, tanto as atitudes quanto as crenças sobre educação vêm dos especialistas como os pediatras, os professores e os psicólogos. A orientação passa a ser a de permitir, não tolher e procurar olhar as crianças nas suas especificidades.

\footnotetext{
O presente artigo apresenta parte dos dados da tese de doutorado em Psicologia (USP) da primeira autora sob orientação da segunda. Título: "Concepções e práticas de pais sobre educação de filhos".

* Doutora em Psicologia (USP). Professora do Mestrado em Família na Sociedade Contemporânea (Universidade Católica do Salvador).

** Professora da Faculdade de Filosofia, Ciência e Letras de Ribeirão Preto (USP).
} 
Particularmente sobre liberdade $\mathrm{x}$ restrições, Biasoli-Alves ${ }^{1}$ questiona o fato de as crianças atualmente serem consideradas muito mais livres do que antes. Para ela, embora seja real a preocupação com o desenvolvimento da independência/autonomia infantil, bem como a presença de uma prática de educação que procura promovê-la, a criança recebe muitas cobranças dos adultos para que se comporte bem e corresponda ao investimento que fazem para que venha a ter um bom futuro. A própria evolução do espaço físico vai do amplo para o restrito, da ausência de controle (liberdade de deslocamento de um lugar a outro) para o ambiente restrito do apartamento. E, em muitos casos, a rua desaparece enquanto ambiente de brincadeiras e encontros.

Analisando as práticas de cuidado e de educação da criança, a autora refere que, antes, a educação estava totalmente apoiada na autoridade dos pais sobre os filhos, havendo delimitações claras do certo e do errado e exigência de cumprimento de normas preestabelecidas. No espaço de algumas décadas, segundo ela, a educação transformou-se profundamente, e ter poucas regras a seguir é caracterizado como ideal e, embora a obediência às ordens dos adultos seja valorizada, o fundamento da educação é dar independência, promover a competência/competitividade e permitir a iniciativa do filho. Biasoli-Alves ${ }^{1}$ atribui tais elementos como sendo fruto do pensamento democrático que influenciou as sociedades ocidentais, inclusive a brasileira. Para ela, vigora um processo de socialização permeado por contradições sendo previsto um tempo longo de dependência econômica dos pais e, por outro lado, uma autonomia precoce com ausência de regras fixas para o comportamento adequado. Hoje, as famílias colocam-se numa situação de insegurança, questionam se estão agindo corretamente com os próprios filhos. Isto é esperado numa sociedade em constante transformação: no lugar das velhas regras, aparecem diversas opções novas que, embora válidas, são criticáveis e também difíceis, muitas vezes, de serem seguidas.

Em um estudo que focalizou a educação da criança no início do século XX, Caldana ${ }^{6}$ entrevistou 20 pessoas de ambos os sexos, nascidas entre os anos de 1895 e 1919, oriundas de famílias de camada média (mas, quando eram crianças tinham condição socioeconômica diversa). Verificou que era em torno dos brinquedos e das brincadeiras que o cotidiano das crianças se dava, independentemente da posse de objetos específicos porque tudo era transformado e os brinquedos disponíveis eram geralmente artesanais, e feitos pelos adultos junto com as crianças.

Muitas delas dispunham de seu tempo livremente, brincavam o quanto quisessem, ou o dividiam com atividades escolares; as que trabalhavam o faziam em conjunto com seus pais, sobretudo na zona rural. Quanto aos locais em que vivenciaram a infância, os participantes da pesquisa de Caldana $^{6}$ mencionaram a amplidão de espaço e a liberdade, mas isto às vezes expunha as crianças a perigos, tornando-as vítimas de acidentes. Conforme Caldana ${ }^{6}$, os adultos, particularmente os pais, educavam as crianças visando a que fossem obedientes. Comparando com os tempos atuais, a autora aponta a emergência de dificuldades hoje sentidas pelos pais na educação dos filhos como o estabelecimento de limites ao desejo e a sociedade de consumo, embora a criança esteja colocada numa posição privilegiada perante o adulto, que se preocupa em respeitar a sua individualidade, em fazê-la feliz e em diminuir a distância entre ambos.

Ao estudar três grupos de mães de camada média do interior paulista, o primeiro constituído pelas que tiveram filhos pequenos nas décadas de 30-40, o segundo nas de 50-60 e o terceiro nas de 70-80, Dias-da-Silva ${ }^{7}$ realizou análises inter e intra-grupos e identificou a existência de certas modificações expressivas tanto nas práticas quanto nas concepções empregadas por tais mães na educação dos filhos.

E ela destaca como resultados da pesquisa que: 1. as mães com filhos pequenos nas décadas de 30-40 priorizavam o controle e a disciplina da criança, apresentando um ideário para educação que abrangia: nível alto de exigência dos filhos, com pouca demonstração de afeto e comunicação, focalizando o desenvolvimento de 
bons hábitos e normas de convivência social. A sexualidade devia ser inibida e a independência do filho pequeno não era relevante e, ao avaliarem a educação de outras épocas, estas mães criticaram as das décadas de 70-80, desaprovando a grande permissividade utilizada, mas valorizando o envolvimento e a afetividade delas para com seus filhos. 2: As com filhos pequenos nas décadas de 50-60 consideravam importante tanto o estabelecimento de exigências quanto a manifestação de afetividade (impondo normas e acariciando/elogiando as crianças). A independência era pouco valorizada e também a comunicação. A inibição da sexualidade foi mantida; elas vigiavam certas condutas dos filhos, envolvendo-se em atividades lúdicas com eles, que costumavam brincar tanto com parentes quanto com vizinhos, no quintal ou em casa; elas criticaram as mães das décadas de 70-80, desaprovando a grande permissividade utilizada na educação dos filhos e a dependência dos especialistas, mas também disseram que aprovavam seu envolvimento e a demonstração de afeto para com eles. 3: As mães com filhos pequenos nas décadas de 7080 , tomando por base as consequiências negativas atribuídas à rigidez e ao autoritarismo dos pais, procuravam estabelecer exigências de nível médio e com certa flexibilidade, visando tanto a favorecer a independência da criança quanto valorizar a comunicação com ela, destacando ainda a demonstração de afeto.

Nesta época as atividades das crianças foram menos supervisionadas pelas mães: já existia a televisão e surge o brinquedo solitário dentro de casa, mantendo-se a possibilidade de elas colaborarem com as tarefas domésticas. Ao contrário das de décadas anteriores, elas aceitavam manifestações de descontentamento por parte dos filhos, considerando que os pais deveriam ter uma participação integral no processo de educação dos filhos, sendo o cuidar deles uma função do casal, embora na prática, as mães assumissem efetivamente a maior parte destas tarefas; suas críticas voltaram-se às mães das décadas de 3040 por terem abusado do autoritarismo e da rigidez na educação dos filhos.

Os dados da pesquisa de Dias-da-Silva ${ }^{7}$ revelam que se caminhou de um pólo mais autori- tário, focalizando a obediência e a disciplina, para um de maior flexibilidade, liberdade e permissividade. Segundo a autora os pais atualmente apresentam uma grande insegurança quanto ao que fazer, o que pode advir do fato de as mães não terem tido a oportunidade de aprender com os mais velhos, ou porque passaram a questionar a maneira como foram educadas, e, ao escapar da sabedoria popular que orientava as gerações anteriores nos cuidados com os filhos, as mães atuais norteiam-se por um ideário mais científico, seguindo orientações de especialistas e de manuais, visando a garantir sua boa maternidade.

Por sua vez, Arriagada ${ }^{8}$ analisa as mudanças nas famílias latino-americanas e constata o decréscimo das taxas de natalidade durante os anos 70 , assinalando que as funções de cuidado e de socialização inicial dos filhos são compartilhadas cada vez mais com outros agentes sociais como a escola, outras pessoas da família e não familiares, havendo novas relações entre pais e filhos, com aumento dos direitos dos filhos e perda da relevância das relações de hierarquia e de submissão. Nesta direção, Godelier ${ }^{9}$ afirma que o que mudou fundamentalmente no Ocidente, no que concerne ao parentesco, foi: a relação das pessoas com a sexualidade, o lugar dos homens e das mulheres na sociedade, e assim a relação entre os sexos, e o lugar das crianças. Para Sirota ${ }^{10}$, como decorrência do exposto anteriormente, olhares para a construção científica do objeto conduziram à criança como uma variável em si: "As transformações dos modos de vida familiares levaram a demografia a reconstruir uma variável que ela ignorava até então, mas que parece se tornar incontornável, pois aparece como o único ponto fixo da célula familiar" (p. 25). Para a autora, a criança como único ponto fixo da família, a tira, assim, de sua invisibilidade, não apenas estatística, mas como agente e ator.

Neste sentido, justifica-se a necessidade de estudos sobre a infância e sua educação nos tempos atuais. Assim, a presente pesquisa se propõe a descrever como mães de nível superior de escolaridade, oriundas de dois contextos do Brasil, relatam as condições oferecidas aos filhos pequenos para que eles participem da de- 
terminação e estruturação das atividades da rotina diária.

Tais dados são comparados aos obtidos por um estudo semelhante de Biasoli-Alves e Caldana ${ }^{11}$ em que foram entrevistadas 110 mães com nível educacional médio-alto e com filhos de três a oito anos de idade, utilizando o mesmo instrumento ${ }^{\text {a }}$ que o empregado na presente pesquisa. Os resultados revelaram haver poucas normas para as quais as mães exigem cumprimento, principalmente as ligadas à higiene e à saúde, ou a comportamentos demasiadamente perturbadores, que elas dizem dar liberdade de escolha aos filhos, permitindo que tomem suas iniciativas, procurando estruturar a vida em termos de horários e organização da casa, mas sendo sensíveis ao que as crianças solicitam.

\section{MÉTODO}

Após um estudo piloto, 50 mulheres de nível universitário, com união marital estável e pelo menos um filho na faixa-etária entre dois e sete anos fizeram parte desta pesquisa. Estas participantes, divididas em dois grupos, foram selecionadas em duas universidades privadas, sendo uma em cidade de porte médio do interior de São Paulo e outra localizada em capital do Nordeste, garantindo-se, assim, o grau de escolaridade desejado (universitário completo) e também a diversidade de formação.

Características das mães: a) idade: $68 \%$ tinham entre 30 e 39 anos; b) estado civil: $95 \%$ eram casadas; c) nível educacional: $100 \%$ tinham nível superior; d) religião: 64\% eram católicas.

Para atingir os objetivos, foi utilizado o "Roteiro reestruturado de Biasoli-Alves e Graminha" ${ }^{12}$, na forma de questionário.

Os procedimentos foram: pedido de autorização por escrito à direção das universidades; convite às alunas; assinatura, por parte das participantes, do Termo de Consentimento Livre e Esclarecido; solicitação do preenchimento e devolução do "Roteiro reestruturado de Biasoli-
Alves e Graminha" ${ }^{12}$, sendo o mesmo para os dois grupos de mães.

Posteriormente à coleta, foram analisados os resultados obtidos a partir de 44 questões $^{\mathrm{b}}$ do referido roteiro, que investigam a forma como a rotina diária acontece, em termos da existência de regras e seu conteúdo e do direcionamento das atividades através de alternativas apresentadas em questões fechadas ou abertas, de tipo dicotômico. Para categorização das respostas usou-se como base o sistema estruturado por Biasoli-Alves e Caldana ${ }^{11}$ (p. 234), conforme se apresenta a seguir:

- Determinação da mãe: quando é ela que direciona a situação, observando-se respostas do tipo "sempre é a mãe que escolhe";

- Determinação conjunta: quando a direção da situação fica a cargo da mãe e da criança, verificando-se respostas do tipo "às vezes a mãe escolhe e às vezes a criança escolhe";

- Determinação da criança: quando é esta que direciona a situação - tendo-se respostas do tipo: "sempre é a criança quem escolhe".

Os dados foram agrupados segundo a área, construindo-se perfis em separado para mães do interior de São Paulo e da capital do Nordeste, e reagrupados na construção do perfil geral do grupo.

\section{RESULTADOS}

Na Tabela 1 são apresentados os dados relativos à participação da mãe e da criança na alimentação desta.

Os dados da Tabela 1 mostram que, em alimentação, fica mais por conta da criança apenas o uso dos talheres (opção por colher ou garfo), porque as mães exigem mais, embora considerando a criança (predomínio da determinação conjunta) no horário e local das refeições, o quê e o quanto comer, as interrupções da refeição, o comer aquilo de que não gosta, o "lambiscar"

\footnotetext{
a "Roteiro Reestruturado de Biasoli-Alves e Graminha"12.

b Essas questões dividem-se entre as diferentes áreas da rotina diária, sendo 14 na de alimentação, 13 em sono, sete em atividades, sete em hábitos de higiene e três em contato social.
} 
Tabela 1: Distribuição porcentual de respostas de mães do interior de São Paulo e da capital do Nordeste nas categorias indicativas de sua participação e da criança na determinação dos diversos aspectos investigados na área de alimentação.

\begin{tabular}{|c|c|c|c|}
\hline Situações & $\begin{array}{l}\text { Mães do interior de } \\
\text { São Paulo (\%) }\end{array}$ & $\begin{array}{l}\text { Mães da capital do } \\
\text { Nordeste }(\%)\end{array}$ & Total $(\%)$ \\
\hline \multicolumn{4}{|c|}{ Horário para refeições } \\
\hline $\mathrm{DM}$ & 20 & 08 & 14 \\
\hline DMC & 76 & 84 & 80 \\
\hline DC & 04 & 08 & 06 \\
\hline Total & 100 & 100 & 100 \\
\hline \multicolumn{4}{|c|}{ Comer na mesa com todo mundo } \\
\hline DM & 24 & 28 & 26 \\
\hline $\mathrm{DMC}$ & 76 & 72 & 74 \\
\hline DC & - & - & - \\
\hline Total & 100 & 100 & 100 \\
\hline \multicolumn{4}{|c|}{ Levantar-se ao terminar de comer } \\
\hline DM & 16 & 08 & 12 \\
\hline $\mathrm{DMC}$ & 36 & 56 & 46 \\
\hline DC & 44 & 36 & 40 \\
\hline NR & 04 & - & 02 \\
\hline Total & 100 & 100 & 100 \\
\hline \multicolumn{4}{|l|}{ O que comer } \\
\hline DM & 16 & 16 & 16 \\
\hline DMC & 80 & 76 & 78 \\
\hline DC & 04 & 08 & 06 \\
\hline Total & 100 & 100 & 100 \\
\hline \multicolumn{4}{|c|}{$\mathrm{O}$ quanto comer } \\
\hline DM & 04 & 08 & 06 \\
\hline DMC & 72 & 72 & 72 \\
\hline $\mathrm{DC}$ & 24 & 20 & 22 \\
\hline Total & 100 & 100 & 100 \\
\hline \multicolumn{4}{|c|}{ Sair e voltar para mesa durante a refeição } \\
\hline DM & 08 & 08 & 08 \\
\hline DMC & 76 & 76 & 76 \\
\hline DC & - & 08 & 04 \\
\hline Não acontece & 16 & 08 & 12 \\
\hline Total & 100 & 100 & 100 \\
\hline \multicolumn{4}{|c|}{ Comer aquilo de que não gosta } \\
\hline DM & 36 & 32 & 34 \\
\hline DMC & 60 & 64 & 62 \\
\hline DC & 04 & 04 & 04 \\
\hline Total & 100 & 100 & 100 \\
\hline \multicolumn{4}{|c|}{ Comer fora do horário } \\
\hline DM & 16 & 20 & 18 \\
\hline DMC & 80 & 80 & 80 \\
\hline DC & 04 & - & 02 \\
\hline Total & 100 & 100 & 100 \\
\hline \multicolumn{4}{|c|}{ Comer tudo o que tem no prato } \\
\hline DM & 04 & 08 & 06 \\
\hline DMC & 56 & 72 & 64 \\
\hline DC & 40 & 20 & 30 \\
\hline Total & 100 & 100 & 100 \\
\hline
\end{tabular}




\begin{tabular}{|c|c|c|c|}
\hline \multicolumn{4}{|c|}{ Ordem dos alimentos nas refeições } \\
\hline DM & 48 & 16 & 32 \\
\hline DMC & 44 & 60 & 52 \\
\hline DC & 08 & 24 & 16 \\
\hline Total & 100 & 100 & 100 \\
\hline \multicolumn{4}{|c|}{ Uso dos talheres } \\
\hline $\mathrm{DM}$ & 12 & 12 & 12 \\
\hline DMC & 28 & 36 & 32 \\
\hline $\mathrm{DC}$ & 60 & 52 & 56 \\
\hline Total & 100 & 100 & 100 \\
\hline \multicolumn{4}{|c|}{ Comer com a mão } \\
\hline $\mathrm{DM}$ & 16 & 36 & 26 \\
\hline DMC & 52 & 48 & 50 \\
\hline DC & 32 & 16 & 24 \\
\hline Total & 100 & 100 & 100 \\
\hline \multicolumn{4}{|c|}{ Fazer a refeição vendo TV } \\
\hline $\mathrm{DM}$ & 24 & 32 & 28 \\
\hline $\mathrm{DMC}$ & 68 & 48 & 58 \\
\hline DC & 08 & 20 & 14 \\
\hline Total & 100 & 100 & 100 \\
\hline \multicolumn{4}{|c|}{ Atender pedido especial de comida } \\
\hline $\mathrm{DM}$ & 04 & - & 02 \\
\hline DMC & 64 & 92 & 78 \\
\hline DC & 32 & 08 & 20 \\
\hline Total & 100 & 100 & 100 \\
\hline
\end{tabular}

$\mathrm{DM}=$ Determinação da mãe; DMC=Determinação conjunta; $\mathrm{DC}=$ Determinação da criança; NR=Não respondeu.

(comer fora do horário), o comer tudo que tem no prato, o uso ou não de talheres, ver TV durante a refeição e no atendimento de pedido especial de comida. No se levantar ao terminar de comer, ficou claro o predomínio de determinação da criança $(44 \%)$ nas respostas das mães do interior de São Paulo e da conjunta $(56 \%)$ para as da capital do Nordeste. Na ordem dos alimentos nas refeições, houve uma porcentagem maior de determinação das mães (48\%) do interior de São Paulo e da conjunta (60\%) nas da capital do Nordeste.

Na Tabela 2, são apresentados os dados relativos à participação da mãe e da criança na determinação do horário de dormir.

Na hora de dormir (Tabela 2), as mães do interior de São Paulo deixam à vontade da criança a possibilidade da luz acesa no quarto, entretanto, exigem despedir-se (com "boa noite", "bênção") e dormir de pijama; já o ver livros e o brincar na cama são determinados conjuntamente. As da capital do Nordeste determinam conjuntamente o dizer boa noite e dormir de pijama; por outro lado, ficar com a luz acesa, ver livros e brincar na cama normalmente não acontece, bem como chupar chupeta, o dedo, levantar da cama e voltar a brincar. Para os dois grupos, o predomínio é o da participação tanto da mãe quanto da criança na determinação do ir para a cama, dos horários, do cômodo em que a mãe está, dormir com bicho de estimação, comer ou beber na cama; por outro lado, escovar os dentes é exigido principalmente pelas mães.

A Tabela 3 traz os resultados relativos à participação da mãe e da criança em atividades da rotina.

Na determinação das atividades da criança ao longo do dia, existe, na visão das mães, predominantemente uma escolha em conjunto do uso da casa nas brincadeiras e da TV durante a noite. Há maior interferência das mães na determinação de atividades, horários e no sair sem os pais; por outro lado, o predomínio da determinação da criança acontece na escolha das brincadeiras, sendo que, para as mães do interior de São Paulo, também é mais 
Tabela 2: Distribuição porcentual de respostas das mães do interior de São Paulo e da capital do Nordeste nas classes indicativas de sua participação e da criança na determinação dos diversos aspectos investigados na área de sono.

\begin{tabular}{|c|c|c|c|}
\hline Situações & $\begin{array}{l}\text { Mães do interior de } \\
\text { São Paulo }(\%)\end{array}$ & $\begin{array}{c}\text { Mães da capital do } \\
\text { Nordeste }(\%)\end{array}$ & Total $(\%)$ \\
\hline \multicolumn{4}{|l|}{ Dizer boa noite } \\
\hline DM & 60 & 20 & 40 \\
\hline DMC & 28 & 48 & 38 \\
\hline DC & 12 & 32 & 22 \\
\hline Total & 100 & 100 & 100 \\
\hline \multicolumn{4}{|l|}{ Dormir de pijama } \\
\hline DM & 48 & 36 & 42 \\
\hline $\mathrm{DMC}$ & 44 & 48 & 46 \\
\hline $\mathrm{DC}$ & 08 & 16 & 12 \\
\hline Total & 100 & 100 & 100 \\
\hline \multicolumn{4}{|l|}{ Escovar os dentes } \\
\hline DM & 60 & 56 & 58 \\
\hline $\mathrm{DMC}$ & 28 & 28 & 28 \\
\hline $\mathrm{DC}$ & 12 & 12 & 12 \\
\hline NR & - & 04 & 02 \\
\hline Total & 100 & 100 & 100 \\
\hline \multicolumn{4}{|l|}{ Dormir na cama } \\
\hline DM & 20 & 20 & 20 \\
\hline DMC & 64 & 52 & 58 \\
\hline $\mathrm{DC}$ & 16 & 28 & 22 \\
\hline Total & 100 & 100 & 100 \\
\hline \multicolumn{4}{|l|}{ Horário de dormir } \\
\hline $\mathrm{DM}$ & 24 & 24 & 24 \\
\hline DMC & 64 & 60 & 62 \\
\hline $\mathrm{DC}$ & 12 & 16 & 14 \\
\hline Total & 100 & 100 & 100 \\
\hline \multicolumn{4}{|c|}{ Levantar da cama e voltar a brincar } \\
\hline DM & 32 & 36 & 34 \\
\hline DMC & 24 & 20 & 22 \\
\hline DC & - & - & - \\
\hline Isso não acontece & 44 & 44 & 44 \\
\hline Total & 100 & 100 & 100 \\
\hline \multicolumn{4}{|c|}{ Levantar e ir para o cômodo em que a mãe está } \\
\hline DM & 8 & 16 & 12 \\
\hline DMC & 68 & 64 & 66 \\
\hline DC & 04 & 04 & 04 \\
\hline Isso não acontece & 20 & 16 & 18 \\
\hline Total & 100 & 100 & 100 \\
\hline \multicolumn{4}{|c|}{ Dormir com luz acesa } \\
\hline DM & 04 & 08 & 06 \\
\hline DMC & 16 & 16 & 16 \\
\hline DC & 64 & 24 & 44 \\
\hline Isso não acontece & 16 & 52 & 34 \\
\hline Total & 100 & 100 & 100 \\
\hline \multicolumn{4}{|c|}{ Ver livros e brincar na cama } \\
\hline $\mathrm{DM}$ & 08 & 04 & 06 \\
\hline DMC & 36 & 40 & 38 \\
\hline DC & 28 & 16 & 22 \\
\hline
\end{tabular}




\begin{tabular}{|c|c|c|c|}
\hline Isso não acontece & 28 & 40 & 34 \\
\hline Total & 100 & 100 & 100 \\
\hline \multicolumn{4}{|c|}{ Comer ou beber na cama } \\
\hline DM & 24 & 12 & 18 \\
\hline DMC & 36 & 40 & 38 \\
\hline DC & 08 & 24 & 16 \\
\hline Isso não acontece & 32 & 24 & 28 \\
\hline Total & 100 & 100 & 100 \\
\hline \multicolumn{4}{|c|}{ Dormir com bicho de estimação } \\
\hline $\mathrm{DM}$ & - & - & - \\
\hline DMC & 20 & 16 & 18 \\
\hline DC & 56 & 56 & 56 \\
\hline Isso não acontece & 24 & 28 & 26 \\
\hline$\underline{\text { Total }}$ & 100 & 100 & 100 \\
\hline \multicolumn{4}{|c|}{ Chupar chupeta ou dedo } \\
\hline $\mathrm{DM}$ & 20 & 08 & 14 \\
\hline DMC & 04 & 04 & 04 \\
\hline DC & 16 & 04 & 10 \\
\hline Isso não acontece & 60 & 84 & 72 \\
\hline Total & 100 & 100 & 100 \\
\hline
\end{tabular}

DM= Determinação da mãe; DMC=Determinação conjunta; DC=Determinação da criança; NR=Não respondeu.

Tabela 3: Distribuição porcentual de respostas de mães do interior de São Paulo e da capital do Nordeste nas classes indicativas de sua participação e da criança na determinação dos diversos aspectos investigados na área de atividades.

\begin{tabular}{|c|c|c|c|}
\hline Situações & $\begin{array}{c}\text { Mães do interior de } \\
\text { São Paulo }(\%)\end{array}$ & $\begin{array}{c}\text { Mães da capital do } \\
\text { Nordeste }(\%)\end{array}$ & Total $(\%)$ \\
\hline \multicolumn{4}{|c|}{ Determinação de atividades e horários } \\
\hline DMC & 44 & 40 & 42 \\
\hline $\mathrm{DC}$ & 08 & 08 & 08 \\
\hline \multicolumn{4}{|c|}{ Escolha de brinquedos nas compras } \\
\hline DM & 12 & 04 & 08 \\
\hline DMC & 36 & 48 & 42 \\
\hline$\underline{\mathrm{DC}}$ & 52 & 48 & 50 \\
\hline DMC & 44 & 40 & 42 \\
\hline DC & 56 & 60 & 58 \\
\hline Total & 100 & 100 & 100 \\
\hline \multicolumn{4}{|c|}{ Sair sem os pais } \\
\hline DM & 100 & 96 & 98 \\
\hline DMC & - & - & - \\
\hline DC & - & - & - \\
\hline NR & - & 04 & 02 \\
\hline Total & 100 & 100 & 100 \\
\hline \multicolumn{4}{|c|}{ Uso da casa nas brincadeiras } \\
\hline
\end{tabular}




\begin{tabular}{llll} 
DC & - & - & - \\
\hline Total & 100 & 100 & 100 \\
\hline Uso da TV durante o dia & 12 & 12 & 12 \\
DM & 44 & 64 & 54 \\
DMC & 44 & 24 & 34 \\
DC & 100 & 100 & 100 \\
\hline Total & 16 & 24 & 20 \\
Uso da TV durante a noite & 84 & 76 & 80 \\
DM & - & - & - \\
DMC & 100 & 100 & 100 \\
DC &
\end{tabular}

$\mathrm{DM}=$ Determinação da mãe; DMC=Determinação conjunta; $\mathrm{DC}=$ Determinação da criança; NR=Não respondeu.

freqüente que a criança escolha os brinquedos; interessante observar que o uso da TV durante o dia e, mais ainda à noite, possui uma determinação conjunta, ou seja, parece existir um acordo entre o adulto e a criança para definir o que vai ou não ser visto, verificando-se ainda uma pequena diferença entre as mães da cidade do interior de São Paulo e as da capital, sendo que, entre as primeiras, é mais freqüente deixar a escolha por conta da criança durante o dia.

Outro aspecto investigado, que diz respeito a quem toma as decisões nas situações de contato social, está exposto na Tabela 4.

Tabela 4: Distribuição porcentual de respostas das mães do interior de São Paulo e da capital do Nordeste nas classes indicativas de sua participação e da criança na determinação dos diversos aspectos investigados na área de contato social.

\begin{tabular}{|c|c|c|c|}
\hline Situações & $\begin{array}{c}\text { Mães do interior de } \\
\text { São Paulo }(\%)\end{array}$ & $\begin{array}{c}\text { Mães da capital do } \\
\text { Nordeste }(\%)\end{array}$ & Total $(\%)$ \\
\hline \multicolumn{4}{|c|}{ Fazer amigos $*$} \\
\hline $\mathrm{DMC}$ & 32 & 48 & 40 \\
\hline DC & 68 & 52 & 60 \\
\hline \multicolumn{4}{|c|}{ Contato com amigos } \\
\hline $\mathrm{DM}$ & 12 & 16 & 14 \\
\hline DMC & 76 & 64 & 70 \\
\hline$\underline{\mathrm{DC}}$ & 12 & 20 & 16 \\
\hline$\underline{\text { Total }}$ & 100 & 100 & 100 \\
\hline
\end{tabular}

* OBS: N=21 para mães da capital do Nordeste e N=22 para mães do interior de São Paulo.

$\mathrm{DM}=$ Determinação da mãe; DMC=Determinação conjunta; DC=Determinação da criança.

Os resultados evidenciam que, se de um lado o fazer amigos é mais diretamente determinado pelas crianças, por outro, o contato com eles é vinculado a decisões conjuntas.

Quanto à maneira de as mães relatarem sua forma de agir diante dos hábitos de higiene, os resultados obtidos acham-se na Tabela 5.

De acordo com as respostas dos dois grupos, aparece um predomínio da participação con- junta mãe e criança na definição dos quatro itens: horário de banho; escolha da roupa; guardar a roupa e brincar com água, areia, terra, sendo bem pequeno o número de mães que refere dar autonomia à criança para fazer suas opções.

$\mathrm{Na}$ sequiência, agrupando-se os dados das Tabelas 1, 2, 3, 4 e 5, foram calculadas as porcentagens por área, construindo-se perfis, em separado, para mães do interior de São Paulo e 
Tabela 5: Distribuição porcentual de respostas das mães do interior de São Paulo e da capital do Nordeste nas classes indicativas de sua participação e da criança na determinação dos diversos aspectos investigados na área de hábitos de higiene e cuidados pessoais.

\begin{tabular}{|c|c|c|c|}
\hline Situações & $\begin{array}{l}\text { Mães do interior de } \\
\text { São Paulo (\%) }\end{array}$ & $\begin{array}{l}\text { Mães da capital do } \\
\text { Nordeste }(\%)\end{array}$ & Total $(\%)$ \\
\hline \multicolumn{4}{|c|}{ Horário de banho } \\
\hline DM & 16 & 12 & 14 \\
\hline DMC & 84 & 80 & 82 \\
\hline DC & - & 08 & 04 \\
\hline Total & 100 & 100 & 100 \\
\hline \multicolumn{4}{|c|}{ Escolha da roupa } \\
\hline DM & 08 & 04 & 06 \\
\hline DMC & 92 & 92 & 92 \\
\hline DC & - & 04 & 02 \\
\hline Total & 100 & 100 & 100 \\
\hline \multicolumn{4}{|c|}{ Guardar a roupa } \\
\hline $\mathrm{DM}$ & 16 & 16 & 16 \\
\hline DMC & 64 & 52 & 58 \\
\hline DC & 20 & 32 & 26 \\
\hline Total & 100 & 100 & 100 \\
\hline \multicolumn{4}{|c|}{ Brincar com água, areia, terra. } \\
\hline DM & 04 & 20 & 12 \\
\hline DMC & 96 & 80 & 88 \\
\hline DC & - & - & - \\
\hline Total & 100 & 100 & 100 \\
\hline
\end{tabular}

$\mathrm{DM}=$ Determinação da mãe; DMC=Determinação conjunta; $\mathrm{DC}=$ Determinação da criança.

Figura 1: Perfil das participantes do interior de São Paulo em termos da participação da mãe e da criança na determinação das atividades da rotina diária, nas áreas de alimentação, sono, atividades, contato social e hábitos de higiene e cuidados pessoais.

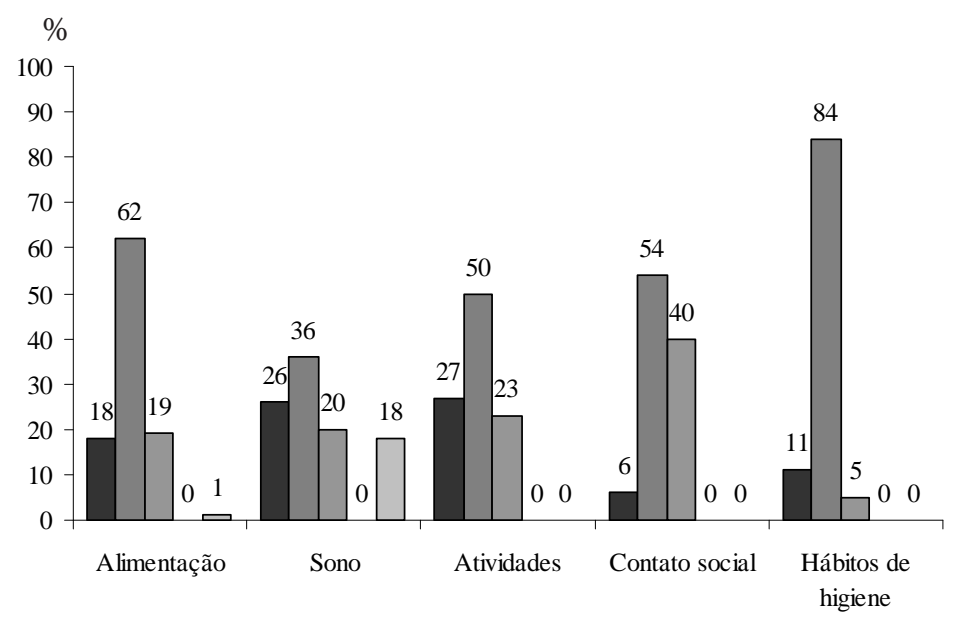


Figura 2: Perfil das participantes da capital do Nordeste em termos da participação da mãe e da criança na determinação das atividades da rotina diária, nas áreas de alimentação, sono, atividades, contato social e hábitos de higiene e cuidados pessoais.

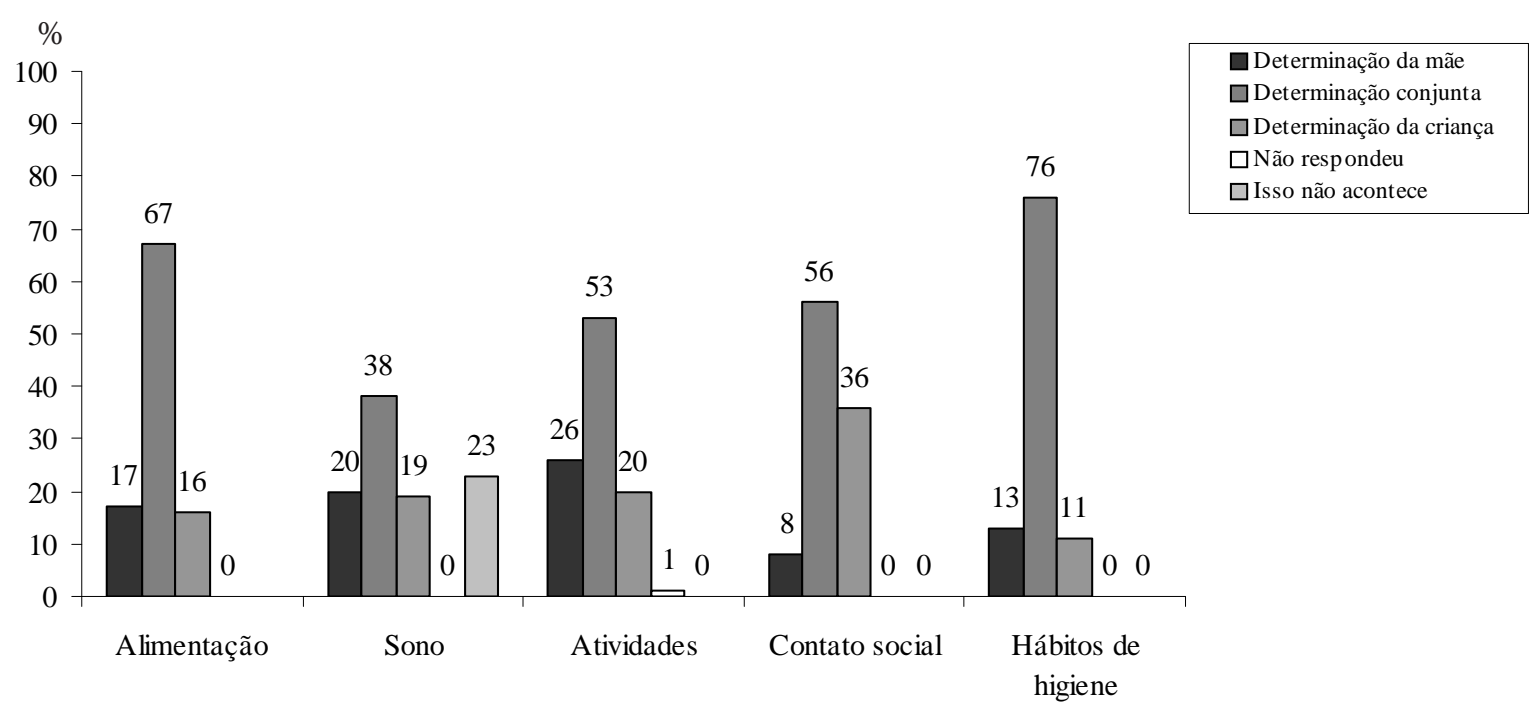

Figura 3: Perfil das participantes em termos da participação da mãe e da criança na determinação da rotina diária, incluindo todas as áreas.

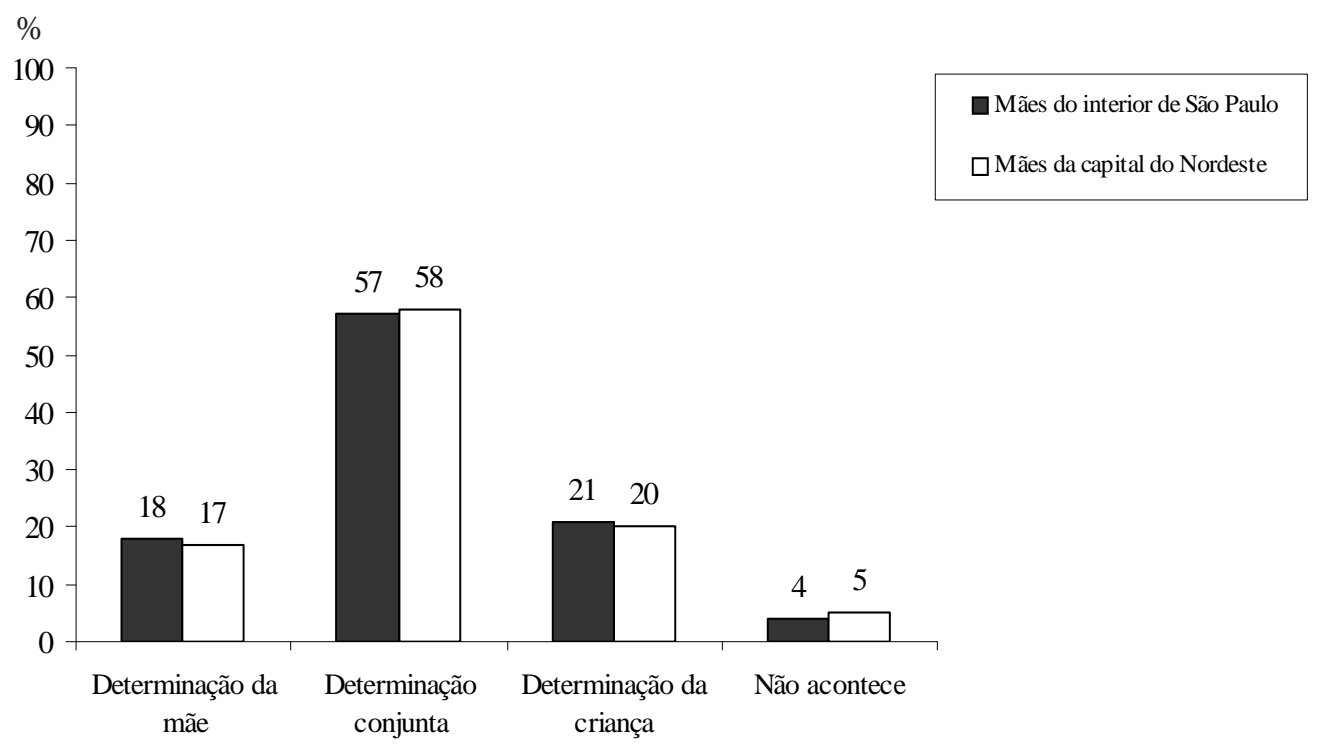


da capital do Nordeste.

Os resultados acham-se nas Figuras 1 e 2.

As Figuras 1 e 2 mostram que a maneira de as mães conduzirem as atividades da rotina diária é variada, sendo que elas interferem mais ou menos dependendo da área. Ao mesmo tempo, existe grande semelhança entre os dois grupos, com o predomínio da determinação conjunta nas diversas áreas. Isto é intensificado na alimentação e nos hábitos de higiene; no sono, a distribuição é mais eqüitativa entre os três determinantes.

Calculando-se as porcentagens gerais para cada grupo em termos de determinação da mãe, dela e da criança e só desta, com os dados das Figuras 1 e 2, obteve-se o perfil geral da população, conforme mostra a Figura 3.

Novamente se confirma a grande proximidade no tipo de resposta das mães dos dois grupos, revelando-se um espaço maior para as determinações conjuntas.

\section{DISCUSSÃO}

A participação da mãe e da criança na determinação das atividades da rotina diária (abrangendo alimentação, sono, atividades, contato social e hábitos de higiene) mostra, neste estudo, maior frequiência da determinação conjunta (cerca de 60\%), ou seja, mãe e criança tendem a decidir em conjunto qual a direção da situação. Determinação só da criança ou da mãe atinge cerca de $20 \%$ das respostas cada uma. Já esses dados na pesquisa de Biasoli-Alves e Caldana ${ }^{11}$ são bem diferente, havendo predomínio da determinação da criança $(41 \%)$, para depois vir a conjunta (33\%) e, por último a mãe, num patamar menor $(23 \%)$. Destaca-se, neste caso, o fato de que a área de contato social é onde a criança exerce uma influência mais significativa, atingindo índices em torno de 40\%; também é nesta área que a criança atinge seu maior índice de determinação (67\%), na pesquisa de Biasoli-Alves e Caldana ${ }^{11}$.

Ao comparar os dois estudos, constata-se que o espaço que a criança tinha para fazer suas opções foi sendo substituído pelas decisões con- juntas dela com a mãe. Foi apresentado um novo movimento, alterando a direção das mudanças que primeiro ocorreram diminuindo o domínio dos adultos e aumentando o da criança, levando a uma exigência de retorno à maior participação das mães na determinação da rotina, colocando limites ao comportamento do filho e a suas escolhas.

Essas alterações parecem indicar que as famílias foram, ao longo dos últimos anos, retomando o controle, o que pode ter sido influenciado por diferentes fatores, em especial pelo conhecimento técnico-científico buscado pelas mães ${ }^{7,13}$.

Arriagada $^{8}$ assinala que as funções de cuidado e socialização inicial dos filhos são compartilhadas, cada vez mais, com outros agentes sociais como a escola e a instituição de educação infantil. Isto também pode estar influenciando a participação conjunta da criança e da mãe na determinação de seu dia-a-dia pois, em espaços de educação coletiva, já é comum a existência de combinados, de conversas - entre o adulto e as crianças - em que a professora auxilia os alunos a identificarem os comportamentos adequados diante de situações corriqueiras como relacionamento com colegas, higiene, e assim por diante. Além disso, ela sinaliza os limites necessários para uma boa convivência social.

É relevante identificar a bidirecionalidade da educação e do desenvolvimento humano, sendo educador e educando sujeitos ativos ${ }^{3}$. Não se pode negar o papel dos pais como mediadores do desenvolvimento que, atentos ao que os filhos vão manifestando em termos de necessidades, interesses e curiosidades, colaboram para que sejam inseridos no contexto social. Além disso, os pais são fundamentais na transmissão de valores e na compreensão do significado da vida. Portanto, a educação atual tem como desafios formar cidadãos conscientes, responsáveis pelos seus atos e comprometidos com a construção de um bem comum.

Finalmente, o presente estudo aponta para a necessidade de investigações sobre a educação a partir do olhar das crianças, assim como aprofundamentos sobre as concepções e práticas paternas e maternas sobre esse tema, tão importante e sempre atual. 


\begin{abstract}
The child's acquisition of independence can be favored or impeded by the educational practices used by the family. This article intends to describe how university level mothers deal with this aspect in the education of their children, aged 2 to 7 . With this purpose, 50 mothers were interviewed. Twenty-five mothers were residents of a middle-sized city located in a rural area of the state of São Paulo and 25 were residents in the capital city of one of the northeastern states of Brazil. Forty-three questions from "Roteiro Reestruturado de Biasoli-Alves e Graminha" were used. The questions seek to discover whether it is the mother or the child who directs situations in the child's daily routine. The results show that in the majority of instances (around 60\%), there is a joint determination. In other words, both mother and child tend to make the decisions together as to which direction daily routine situations should follow.
\end{abstract}

Keywords: Educational practices; parents and children; middle-class urban families.

\section{REFERÊNCIAS}

1. Biasoli-Alves ZMM. A questão da disciplina na prática de educação da criança, no Brasil, ao longo do século XX. Rev Veritati. 2002; (2): 243-259.

2. Bronfenbrenner U. Uma família e um mundo para o bebé XXI: sonho e realidade. In: Gomes PJ, coordenador. Bebé XXI: criança e família na viragem do século. Lisboa: Fundação Calouste Gulbenkian; 1995. p. 115-126.

3. Bronfenbrenner, U. Making Human Beings: Human Bioecological Perspectives on Human Development. Sage: Califórnia; 2004.

4. Gomes PJ, coordenador. Bebé XXI: criança e família na viragem do século. Lisboa: Fundação Calouste Gulbenkian; 1995.

5. Ribas Jr RC, Moura MLS, Bornstein MH. Cognições maternas acerca da maternidade e do desenvolvimento humano: uma contribuição ao estudo da psicologia parental. Rev Bras Crescimento Desenv Hum 2007; 17 (1): 104-113.

6. Caldana RHL. A criança e sua educação na família no início do século: autoridade, limites e cotidiano. Rev Temas em Psicologia 1998; 6 (2): 87-103.

7. Dias da Silva MHGF. A educação dos filhos pequenos nos últimos 50 anos: a busca do "melhor"? Dissertação de Mestrado, Universidade de São Paulo. Instituto de Psicologia. São Paulo, 1986.

8. Arriagada I. Nuevas familias para um nuevo siglo? Cadernos de Psicologia e Educação: Paidéia. 2000; 18 (10): 28-35.

9. Godelier, M. Métamorphoses de la parenté. Monrouge: Fayard; 2004.

10. Sirota, R. Emergência de uma sociologia da infância: evolução do objeto e do olhar. Cadernos de Pesquisa 2001; 112 (1): 7-22.

11. Biasoli-Alves ZMM, Caldana RHL. Práticas educativas: a participação da criança na determinação de seu dia-a-dia. Rev Psicologia: Teoria e Pesquisa. 1992; 8 (2): 231-242.

12. Biasoli-Alves ZMM. A pesquisa psicológica: análise de métodos e estratégias na construção de um conhecimento que se pretende científico. In: Romanelli G, Biasoli-Alves ZMM. organizadores. Diálogos metodológicos sobre prática de pesquisa. Ribeirão Preto: Legis Summa; 1998. p. 135-158.

13. Biasoli-Alves ZMM, Caldana RHL, Dias da Silva MHGF. Práticas de educação da criança: a emergência do saber técnico-científico. Rev Bras Crescimento Desenv Hum. 1997; 7 (1): 49-62.

Recebido em: 20/09/2007

Modificado em: 23/11/2007

Aprovado em: 12/12/2007 